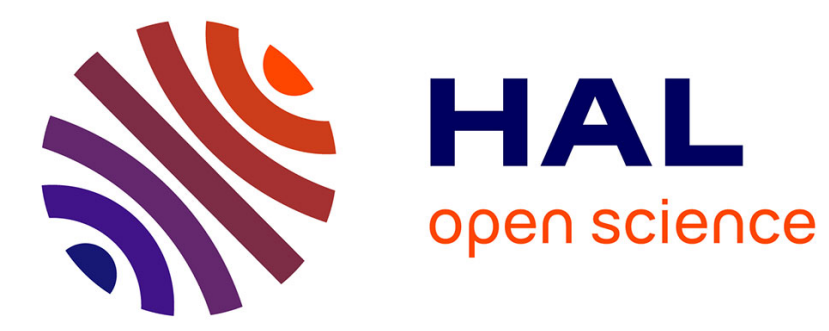

\title{
Risk Factors for Pharyngocutaneous Fistula After Total Pharyngolaryngectomy
}

Emilien Lemaire, Philippe Schultz, Sébastien Vergez, Christian Debry, Jérome Sarini, Benjamin Vairel, Guillaume de Bonnecaze, Catherine Takeda-Raguin, Bastien Cabarrou, Agnès Dupret Bories

\section{To cite this version:}

Emilien Lemaire, Philippe Schultz, Sébastien Vergez, Christian Debry, Jérome Sarini, et al.. Risk Factors for Pharyngocutaneous Fistula After Total Pharyngolaryngectomy. Ear Nose and Throat Journal, 2020, 1 (7), pp.014556131990103. 10.1177/0145561319901035 . hal-03203360

\section{HAL Id: hal-03203360 https://hal.science/hal-03203360}

Submitted on 20 Apr 2021

HAL is a multi-disciplinary open access archive for the deposit and dissemination of scientific research documents, whether they are published or not. The documents may come from teaching and research institutions in France or abroad, or from public or private research centers.
L'archive ouverte pluridisciplinaire HAL, est destinée au dépôt et à la diffusion de documents scientifiques de niveau recherche, publiés ou non, émanant des établissements d'enseignement et de recherche français ou étrangers, des laboratoires publics ou privés. 


\section{Open Archive Toulouse Archive Ouverte (OATAO)}

OATAO is an open access repository that collects the work of Toulouse researchers and makes it freely available over the web where possible

This is a Publisher's version published in: http://oatao.univ-toulouse.fr/27616

Official URL: https://doi.org/10.1177/0145561319901035

\section{To cite this version:}

Lemaire, Emilien and Schultz, Philippe and Vergez, Sébastien and Debry, Christian and Sarini, Jérome and Vairel, Benjamin and de Bonnecaze, Guillaume and Takeda-Raguin, Catherine and Cabarrou, Bastien and Dupret Bories, Agnès $\fallingdotseq$ Risk Factors for Pharyngocutaneous Fistula After Total Pharyngolaryngectomy. (2020) Ear, Nose \& Throat Journal, 1 (7). 014556131990103. ISSN 0145-5613

Any correspondence concerning this service should be sent to the repository administrator: tech-oatao@listes-diff.inp-toulouse.fr 


\title{
Risk Factors for Pharyngocutaneous Fistula After Total Pharyngolaryngectomy
}

\author{
Emilien Lemaire, MD', Philippe Schultz, MD, PhD', \\ Sébastien Vergez, MD, PhD², Christian Debry, MD, PhD' ${ }^{\circledR}$, \\ Jérome Sarini, $M D^{3}$, Benjamin Vairel, $M D^{2}$, \\ Guillaume de Bonnecaze, MD, PhD' ${ }^{2}$, Catherine Takeda-Raguin, MD $^{4}$, \\ Bastien Cabarrou, $\mathrm{PhD}^{5}$, and Agnès Dupret-Bories, $\mathrm{MD}, \mathrm{PhD}^{3}{ }^{\circledR}$
}

\begin{abstract}
Purpose: To evaluate the risk factors of pharyngocutaneous fistula after total pharyngolaryngectomy (TPL) in order to reduce their incidence and propose a perioperative rehabilitation protocol. Materials and Methods: This was a multicenter retrospective study based on 456 patients operated for squamous cell carcinoma by total laryngectomy or TPL. Sociodemographic, medical, surgical, carcinologic, and biological risk factors were studied. Reactive $C$ protein was evaluated on post-op day 5. Patients were divided into a learning population and a validation population with patients who underwent surgery between 2006 and 2013 and between 2014 and 2016, respectively. A risk score of occurrence of salivary fistula was developed from the learning population data and then applied on the validation population (temporal validation). Objective: To use a preoperative risk score in order to modify practices and reduce the incidence of pharyngocutaneous fistula. Results: Four hundred fifty-six patients were included, 328 in the learning population and 128 in the validation population. The combination of active smoking over 20 pack-years, a history of cervical radiotherapy, mucosal closure in separate stitches instead of running sutures, and the placement of a pedicle flap instead of a free flap led to a maximum risk of post-op pharyngocutaneous fistula after TPL. The risk score was discriminant with an area under the receiver operating characteristic curve of $0.66(95 \%$ confidence interval $[\mathrm{Cl}]=0.59-0.73)$ and $0.70(95 \% \mathrm{Cl}$ $=0.60-0.8 \mathrm{I})$ for the learning population and the validation population, respectively. Conclusion: A preoperative risk score could be used to reduce the rate of pharyngocutaneous fistula after TPL by removing I or more of the 4 identified risk factors.
\end{abstract}

\section{Keywords}

pharyngocutaneous fistula, total laryngectomy, total pharyngolaryngectomy, head and neck cancer

\section{Introduction}

Pharyngocutaneous fistula, or pharyngostoma, is a common complication occurring between the 2 nd and 23 rd post-op day after total laryngectomy (TL) or total pharyngolaryngectomy (TPL). ${ }^{1}$ It causes high morbidity, that is, an increase in the length of hospitalization and sometimes requires surgical resumption. The incidence of salivary fistula varies between $3 \%$ and $65 \%$ depending on the study., ${ }^{2,3}$ Three factors have proven significant in several studies and meta-analyses: a history of cervical radiotherapy, post-op anemia, that is, hemoglobinemia of less than $12.5 \mathrm{~g} / \mathrm{dL}$, and perioperative malnutrition, as defined by the criteria of the High Authority of Health (HAS) in 2007. ${ }^{4-6}$

Other factors have been found to be significant only in some studies and remain controversial: size and tumor site, unhealthy surgical margins, post-op antibiotic therapy, preoperative

\footnotetext{
' Department of Otorhinolaryngology, Centre Hospitalo-Universitaire de Hautepierre, Strasbourg, France

${ }^{2}$ Department of Otorhinolaryngology, Hôpital Larrey, Institut Universitaire du Cancer Toulouse Oncopôle, Toulouse, France

${ }^{3}$ Department of Otorhinolaryngology, Head and Neck Surgery, Instititut Claudius Regaud, Institut Universitaire du Cancer Toulouse Oncopôle, Toulouse, France

${ }^{4}$ Department of Geriatric Medicine, Hôpitaux Universitaires de Toulouse, Hôtel Dieu Saint Jacques, Toulouse, France

${ }^{5}$ Biostatistics Unit, Institut Claudius Regaud, Institut Universitaire du Cancer Toulouse Oncopôle, Toulouse, France
}

Received: May 27, 2019; revised: December 10, 2019; accepted: December 23, 2019

\section{Corresponding Author:}

Agnès Dupret-Bories, Department of Otorhinolaryngology, Head and Neck Surgery, Instititut Claudius Regaud, Institut Universitaire du Cancer Toulouse Oncopole, I avenue Irène Joliot Curie, 31059 Toulouse, France.

Email: dupret-bories.agnes@iuct-oncopole.fr 
the $\chi^{2}$ or Fisher exact test for categorical variables and the Mann-Whitney $U$ test for continuous variables.

According to the recommendations of Moons et al, the study population was divided into 2 groups according to the year of surgery in order to perform a temporal validation of the risk score. ${ }^{12}$ Patients who underwent surgery between 2006 and 2013 and between 2014 and 2016 were included in the learning and the validation population, respectively. A risk score was developed from the learning population data. A penalized logistic regression model with elastic net regularization was used to identify factors associated with the occurrence of a salivary fistula. ${ }^{13}$ Using a resampling approach, bootstrap selection stability (BSS) was computed for each factor and only those with a BSS $>70 \%$ were included in the final model. Risk score was created from the associated regression coefficients and then applied on the validation population. The score performance was quantified in terms of discrimination (area under the receiver operating characteristic [ROC] curve, AUC) and calibration (ie, agreement between observed outcome frequencies and probabilities predicted by the risk score) for the learning and the validation population.

The discriminant capacity of RCP was assessed using the AUC curve. The AUC, sensitivity, specificity, positive, and negative predictive values (NPV) were estimated with their 95\% confidence intervals (CIs).

\section{Results}

Five hundred seventy-four patients received a TL, TPL, or CTPL between January 1, 2006, and December 31, 2016. One hundred eighteen were excluded due to lack of data. Among the 456 patients included in the study, 328 were operated between 2006 and 2013 (learning population) and 128 between 2014 and 2016 (validation population). Their characteristics are presented in Table 2 . The study population was $87 \%$ male $(n=397)$ and $45 \%$ of the patients were under 60 years of age. The WHO score was 0 or 1 for most of the population (82\%). Of the 456 patients included, 149 had a pharyngocutaneous fistula (33\%). In $60 \%$ of cases, surgical reoperation was necessary. Average dietary recovery was 11 days versus 45 days for patients without or with salivary fistula, respectively.

The score was developed based on the data from the learning population. Figure 1 presents the results of the Elastic Net BSS selection model. Four risk factors associated with the occurrence of the salivary fistula with a BSS $>70 \%$ were identified. In decreasing order, they were mucosal closure in separate stitches with regard to overlock (BSS $=80.7 \%$ ), a history of cervical radiotherapy (BSS $=77.4 \%$ ), smoking $>20$ PY active (BSS $=73.3 \%$ ), and closure by a pedicle flap in tiletype musculocutaneous flap of the large pectoral compared to a free flap (BSS $=72.9 \%$ ).

The risk score showed good performance in terms of discriminant capacity and calibration on the learning population as well as the validation population. The AUC was $0.66(95 \%$ $\mathrm{CI}=0.59-0.73)$ and $0.70(95 \% \mathrm{CI}=0.60-0.81)$ for the learning and validation population, respectively. Regarding calibration, average $\left(E_{\text {avg }}\right)$ and maximum $\left(E_{\max }\right)$ error was 0.03 and 0.14 for the learning population and 0.06 and 0.21 for the validation population, respectively (Figure 1).

The RCP assay (Table 3) at D5 in 139 patients showed an AUC $=0.77$ (95\% CI $=0.68-0.85)$. Therefore, an RCP less than or equal to $40 \mathrm{mg} / \mathrm{L}$ provided an NPV of $86.96 \%$ and a specificity of $23.53 \%$.

\section{Discussion}

Few risk factors for salivary fistulas have proved significant in recent meta-analyses. Post-op risk factors reported by Paydarfar et al and Liang et al were anemia as defined by hemoglobinemia $<12.5 \mathrm{~g} / \mathrm{dL}$, preoperative tracheotomy, and cervical radiotherapy in the former study, and unhealthy resection margins, tumor size and location, post-op anemia, and cervical radiotherapy in the latter, respectively. ${ }^{4-6}$ These risk factors remain controversial since they were found to be significant in some studies and nonsignificant in others. We found 4 main high-risk factors for pharyngocutaneous fistula: active smoking $>20 \mathrm{PY}$, cervical radiotherapy, mucosal closure at separate points, and pharyngeal closure by pedicle flap. The risk of developing pharyngocutaneous fistula is maximal when all these factors are combined in the same patient, so the aim is to reduce the number of factors present in order to reduce the relative risk. Smoking is known to cause delayed healing in skin surgery due mainly to hypoxia and tissue ischemia associated with dysimmunity. ${ }^{14}$ It may also be responsible for scarring of the pharyngeal mucosa. In 2005, Kuri et al found improved healing in head and neck cancers in patients who had been weaned from smoking 3 weeks before surgery. ${ }^{15}$ Cervical radiotherapy is a known and unmodifiable risk factor. Due to laryngeal preservation protocols, this is an increasingly frequent risk factor, that is, salvage laryngectomy. ${ }^{16}$ Several authors have studied the risk factors for pharyngocutaneous fistula in irradiated territories. Two recent meta-analyses concerning only salvage laryngectomies confirmed that the addition of healthy tissues such as an interposed regional muscle flap (onlay technique) or a pediculate flap or free flap suture in patch form to the pharyngeal mucosa reduces the rate of pharyngocutaneous fistula by one-third. ${ }^{17,18}$

Two intraoperative risk factors were identified, that is, the type of mucosal suture and mucosal closure by pedicle flap. The finding of an increased risk of a mucosal suture with separate stitches compared to an overlock is consistent with 2 other studies. ${ }^{19,20}$ They showed a decrease in pharyngocutaneous fistula rate during overlock pharyngeal closure with 1 fistula in 31 patients and 0 fistula in 13 patients, respectively, in patients who received first-line radical surgical treatment, that is, not in an irradiated territory. Mucosal closure by a pedicle flap rather than a free flap also appears to carry a greater risk. Mucosal closure is a valid procedure when the mucosal resection is too large, and the closure requires a flap. Decreasing the number of these 4 identified risk factors would decrease the rate of pharyngocutaneous fistula. Therefore, a mucosal closure by free flap is preferable to a pedicle flap when possible, with preoperative smoking cessation at least 3 weeks before surgery 
Table 2. Statistical Results of Risk Factors According to Population.

\begin{tabular}{|c|c|c|c|c|}
\hline & $<o r=2013$ & $>2013$ & Total & \\
\hline Year of Surgery & $N=328(\%)$ & $N=128(\%)$ & $N=456(\%)$ & $P$ Value \\
\hline Age, $N=456$ & & & & .04 \\
\hline$<$ or $=60$ years & $160(49)$ & $46(36)$ & $206(45)$ & \\
\hline$>60$ years & $168(5 \mathrm{I})$ & $82(64)$ & $250(55)$ & \\
\hline Sex, $N=456$ & & & & .01 \\
\hline Man & $289(88)$ & $108(84)$ & $397(87)$ & \\
\hline Woman & $39(12)$ & $20(16)$ & $59(13)$ & \\
\hline Smoking, $N=406$ & & & & .24 \\
\hline$<20 \mathrm{PY}$ & $59(22)$ & $19(16)$ & $78(20)$ & \\
\hline$>20 \mathrm{PY}$ & $215(78)$ & $97(84)$ & $312(80)$ & \\
\hline Alcoholism, $N=391$ & & & & .69 \\
\hline Yes & $127(46)$ & $51(44)$ & $178(45)$ & \\
\hline No & 148 (54) & $65(56)$ & $213(55)$ & \\
\hline Diabetes, $N=426$ & & & & .28 \\
\hline Yes & $45(15)$ & 23 (19) & $68(16)$ & \\
\hline No & $260(85)$ & $98(81)$ & $358(84)$ & \\
\hline GERD, $N=416$ & & & & .57 \\
\hline Yes & $20(7)$ & $10(8)$ & $30(7)$ & \\
\hline No & $276(93)$ & $110(92)$ & $386(93)$ & \\
\hline Liver pathology, $N=427$ & & & & .48 \\
\hline Yes & $29(10)$ & $9(7)$ & $38(9)$ & \\
\hline No & $276(90)$ & $113(93)$ & $389(91)$ & \\
\hline Weight loss, $N=347$ & & & & .23 \\
\hline Yes & $77(3 \mathrm{I})$ & $36(37)$ & $113(33)$ & \\
\hline No & $174(69)$ & $60(63)$ & $234(67)$ & \\
\hline Albuminemia, $N=172$ & & & & $<.01$ \\
\hline$<35 \mathrm{~g} / \mathrm{L}$ & $4 I(35)$ & 4 I (75) & $82(48)$ & \\
\hline$>35 \mathrm{~g} / \mathrm{L}$ & $76(65)$ & $14(25)$ & $90(52)$ & \\
\hline Re-feeding, $N=326$ & & & & .01 \\
\hline Yes & 87 (37) & $50(53)$ & $136(42)$ & \\
\hline No & $145(63)$ & $45(47)$ & $190(58)$ & \\
\hline Tracheotomy, $\mathrm{N}=449$ & & & & .06 \\
\hline Yes & $64(20)$ & $36(28)$ & $100(22)$ & \\
\hline No & $257(80)$ & $92(72)$ & $349(78)$ & \\
\hline Radiotherapy, $N=453$ & & & & .09 \\
\hline Yes & $98(30)$ & $49(38)$ & 147 (32) & \\
\hline No & $227(70)$ & $79(62)$ & $306(68)$ & \\
\hline Chemotherapy, $N=453$ & & & & .28 \\
\hline Yes & 71 (22) & $34(27)$ & $105(23)$ & \\
\hline No & $254(78)$ & $94(73)$ & $348(77)$ & \\
\hline Surgery, $N=456$ & & & & .08 \\
\hline $\mathrm{TL}$ & $160(49)$ & $68(53)$ & $228(50)$ & \\
\hline TPL & $156(47)$ & $50(39)$ & $206(45)$ & \\
\hline CTPL & $12(4)$ & $10(8)$ & $22(5)$ & \\
\hline Node dissection, $\mathrm{N}=455$ & & & & .44 \\
\hline Yes & $255(78)$ & $104(81)$ & $358(79)$ & \\
\hline No & $72(22)$ & $24(19)$ & $96(2 I)$ & \\
\hline Pharyngeal closure, $N=449$ & & & & $<.01$ \\
\hline Direct closure & $267(83)$ & 101 (79) & $368(82)$ & \\
\hline Pedicle flap & $50(16)$ & $13(10)$ & $63(14)$ & \\
\hline Free flap & $4(1)$ & $14(1 \mathrm{I})$ & $18(4)$ & \\
\hline Pharyngeal stitch, $N=413$ & & & & .71 \\
\hline Overlock thread & $3 I(I I)$ & $15(13)$ & $46(\mathrm{II})$ & \\
\hline Separated point & $253(86)$ & $99(83)$ & $352(85)$ & \\
\hline Staples & $10(3)$ & $5(4)$ & $15(4)$ & \\
\hline Pharyngeal covering, $N=454$ & & & & .18 \\
\hline Yes & $59(18)$ & $30(24)$ & $89(20)$ & \\
\hline No & $268(82)$ & $97(76)$ & $365(80)$ & \\
\hline
\end{tabular}


Table 2. (continued)

\begin{tabular}{|c|c|c|c|c|}
\hline & $<o r=2013$ & $>2013$ & Total & \\
\hline Year of Surgery & $N=328(\%)$ & $N=128(\%)$ & $N=456(\%)$ & $P$ Value \\
\hline Tracheoesophageal prosthesis: $(\mathrm{N}=45 \mathrm{I})$ & & & & .03 \\
\hline Yes & $160(49)$ & $48(38)$ & $208(46)$ & \\
\hline Non & $165(5 \mathrm{I})$ & $78(62)$ & $243(54)$ & \\
\hline Salivary tube, $N=455$ & & & & .35 \\
\hline Yes & $20(6)$ & II (9) & $31(7)$ & \\
\hline No & $307(94)$ & $117(91)$ & $424(93)$ & \\
\hline NGT, $N=435$ & & & & .98 \\
\hline Yes & $258(83)$ & $103(83)$ & $361(83)$ & \\
\hline No & $53(17)$ & $21(17)$ & $74(17)$ & \\
\hline Resection margins, $\mathrm{N}=442$ & & & & .67 \\
\hline Ro & $239(76)$ & $95(74)$ & $334(76)$ & \\
\hline RI-R2 & 75 (24) & $33(26)$ & $108(24)$ & \\
\hline Tumor stage, $N=420$ & & & & .96 \\
\hline TI-T2 & $30(10)$ & $12(10)$ & $42(10)$ & \\
\hline $\mathrm{T} 3$ & $73(24)$ & $27(23)$ & $100(24)$ & \\
\hline $\mathrm{T} 4$ & $199(66)$ & $79(67)$ & $278(66)$ & \\
\hline Hemoglobinemia, $N=344$ & & & & .79 \\
\hline$<12.5 \mathrm{~g} / \mathrm{dl}$ & $195(86)$ & $103(87)$ & $298(87)$ & \\
\hline$>12.5 \mathrm{~g} / \mathrm{dl}$ & 31 (14) & $15(13)$ & $46(13)$ & \\
\hline Blood transfusion, $\mathrm{N}=263$ & & & & .37 \\
\hline Yes & $53(30)$ & $31(36)$ & $84(32)$ & \\
\hline No & $123(70)$ & $56(64)$ & $179(68)$ & \\
\hline Drainage, $N=130$ & & & & .49 \\
\hline$<48$ hours & 7 (8) & $2(4)$ & $9(7)$ & \\
\hline$>48$ hours & $77(92)$ & $44(96)$ & $121(93)$ & \\
\hline
\end{tabular}

Abbreviations: GERD, gastroesophageal reflux disease; TL, total laryngectomy; TPL, total pharyngolaryngectomy.

Note. The numbers in brackets are the medians.

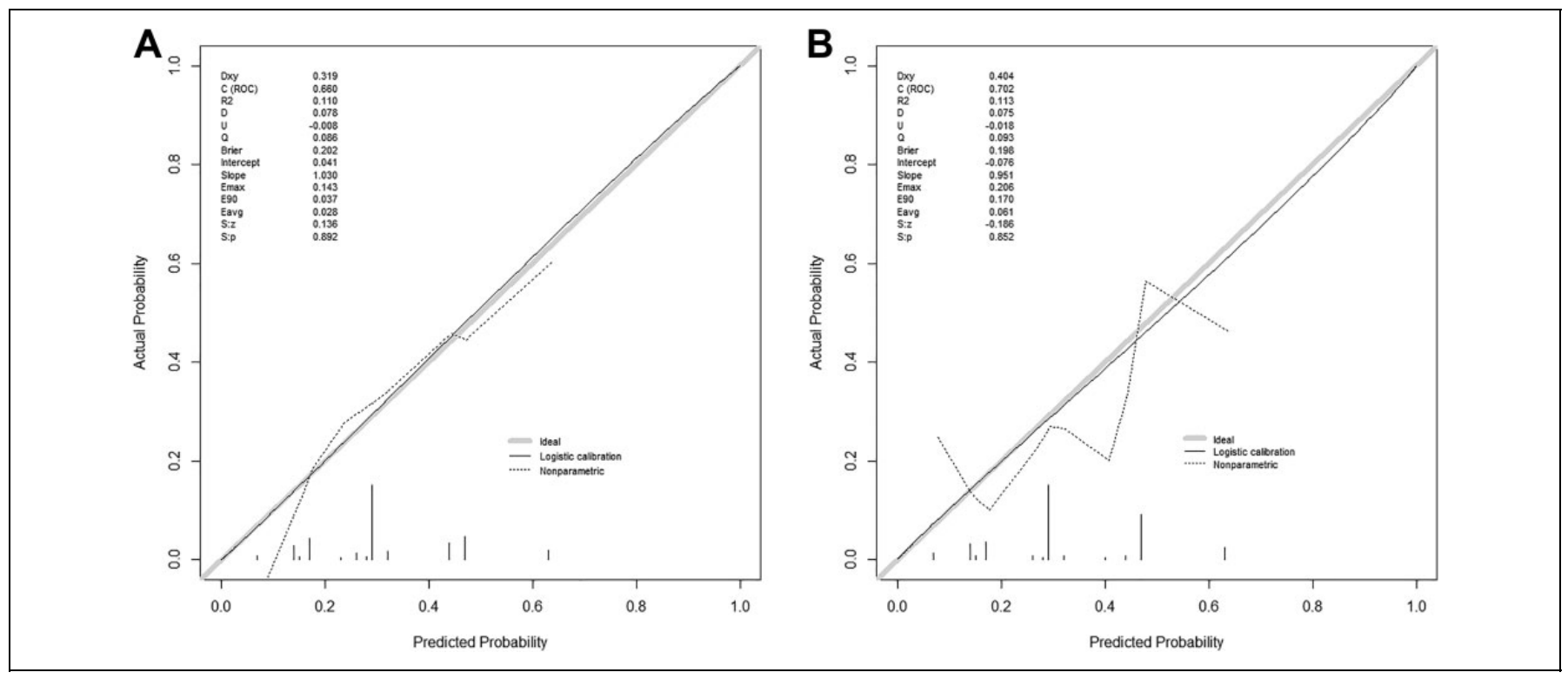

Figure I. Elastic net/bootstrap selection stability. Calibration: A, learning population; B, Validation population.

and a mucosal suture by overlock for selected subjects. It should be noted that we performed running sutures only as simple sutures and not for mucosal closure by flaps.

We also analyzed post-op RCP levels. An RCP at D5 less than or equal to $40 \mathrm{mg} / \mathrm{L}$ had a NPV of $87 \%$ and a specificity of
24\%. The analysis of RCP at D5 is useful when deciding on early refeeding. Some authors found no significant difference in the occurrence of pharyngocutaneous fistula between a recharge at D5 or D10 in patients who had had first-line surgery (unirradiated neck). ${ }^{21}$ Krouse et al in 1992 established the 
Table 3. Statistical Analysis of RCP at Day 5.

\begin{tabular}{lccc}
\hline & \multicolumn{2}{c}{ Pharyngostoma } & \\
\cline { 2 - 3 } RCP $(\mathrm{mg} / \mathrm{L})$ & NO & YES & Total \\
\hline$<40$ & 20 & 3 & 23 \\
$>40$ & 65 & 51 & 116 \\
Total & 85 & 54 & 139 \\
\hline & & $\%$ & $95 \%$ Confidence Interval \\
\hline Sensitivity & & $94.44 \%$ & $90.64-98.25$ \\
Specificity & $23.53 \%$ & $16.48-30.58$ \\
Positive predictive value & $43.97 \%$ & $35.71-52.22$ \\
Negative predictive value & $86.96 \%$ & $81.36-92.56$ \\
\hline
\end{tabular}

Abbreviation: $\mathrm{RCP}$, reactive $\mathrm{C}$ protein.

indication of post-op POT of a TL or TPL to predict the occurrence of pharyngocutaneous fistula. ${ }^{22}$ Pharyngeal-esophageal transit has a specificity of $94 \%$ according to White et al, and RCP has NPV of $87 \%$ in our hands. ${ }^{23}$ Combining an RCP assay on D5 with a POT would allow early refeeding and reduce time in hospital.

\section{Conclusion}

The combination of smoking $>20$ PY active, a history of cervical radiotherapy, mucosal closure at separate points with regard to overlock and the placement of a pedicle flap with regard to a free flap represents a maximum risk of post-op saliva fistula after (P)LT.

Reducing the number of these factors could reduce the incidence of salivary fistulas. In the context of early refeeding, an RCP level of RCP $<40 \mathrm{mg} / \mathrm{L}$ at D5 post-op and POT without signs of fistula have a good NPV. Reducing the incidence of salivary fistulas and achieving early refeeding is part of a perioperative rehabilitation program to be evaluated.

\section{Acknowledgments}

We thank our colleagues Gaël Espinasse, MD and Jean Carvalho, MD who participated in discussions and managed patients.

\section{Declaration of Conflicting Interests}

The author(s) declared no potential conflicts of interest with respect to the research, authorship, and/or publication of this article.

\section{Funding}

The author(s) received no financial support for the research, authorship, and/or publication of this article.

\section{ORCID iDs}

Christian Debry (D) https://orcid.org/0000-0002-0268-0535 Agnès Dupret-Bories (D https://orcid.org/0000-0002-7068-3500

\section{References}

1. Mattioli F, Bettini M, Molteni G, et al. Analysis of risk factors for pharyngocutaneous fistula after total laryngectomy with particular focus on nutritional status. Acta Otorhinolaryngol Ital Organo Uff Della Soc Ital Otorinolaringol E Chir Cerv-facc. 2015;35(4): 243-248.

2. Thawley SE. Complications of combined radiation therapy and surgery for carcinoma of the larynx and inferior hypopharynx. Laryngoscope. 1981;91(5):677-700.

3. Bresson K, Rasmussen H, Rasmussen PA. Pharyngo-cutaneous fistulae in totally laryngectomized patients. J Laryngol Otol. 1974;88(9):835-842.

4. Liang JW, Li ZD, Li SC, Fang FQ, Zhao YJ, Li YG. Pharyngocutaneous fistula after total laryngectomy: a systematic review and meta-analysis of risk factors. Auris Nasus Larynx. 2015; 42(5):353-359.

5. Dedivitis RA, Aires FT, Cernea CR, Brandão LG. Pharyngocutaneous fistula after total laryngectomy: systematic review of risk factors. Head Neck. 2015;37(11):1691-1697.

6. Paydarfar JA, Birkmeyer NJ. Complications in head and neck surgery: a meta-analysis of postlaryngectomy pharyngocutaneous fistula. Arch Otolaryngol Head Neck Surg. 2006;132(1):67-72.

7. Kiliç C, Tuncel U, Cömert E. Pharyngocutaneous fistulae after total laryngectomy: analysis of the risk factors and treatment approaches. B-ENT. 2015;11(2):95-100.

8. Cavalot AL, Gervasio CF, Nazionale G, et al. Pharyngocutaneous fistula as a complication of total laryngectomy: review of the literature and analysis of case records. Otolaryngol-Head Neck Surg Off J Am Acad Otolaryngol-Head Neck Surg. 2000;123(5):587-592.

9. Horgan EC, Dedo HH. Prevention of major and minor fistulae after laryngectomy. Laryngoscope. 1979;89(2 Pt 1):250-260.

10. Alfonsi P, Slim K, Chauvin M, Mariani P, Faucheron J-L, Fletcherf $\mathrm{D}$, le groupe de travail de la Société française d'anesthésie et réanimation(Sfar) et de la Société française de chirurgie digestive (SFCD). Guidelines for enhanced recovery after electivecolorectal surgery. Annales Françaises d'Anesthésie et de Réanimation 33(2014):370-384. http://sfar.org/wp-content/uploads/2015/10/ 2_AFAR_Rehabilitation-rapide-apres-une-chirurgie-colorectaleprogrammee.pdf. Cited July 1, 2017.

11. https://www.hassante.fr/portail/upload/docs/application/force download/2016-09/synthese_raac_2016-09-01_15-49-32_230. pdf. Cited July 18, 2017.

12. Moons KG, Altman DG, Reitsma JB, et al. Transparent Reporting of a multivariable prediction model for Individual Prognosis or Diagnosis (TRIPOD): explanation and elaboration. Ann Intern Med. 2015;162(1):W1-73.

13. Zou H, Hastie T. Regularization and variable selection via the elastic net. J R Statist Soc B. 2005;67(Part 2):301-320.

14. Pluvy I, Garrido I, Pauchot J, et al. Smoking and plastic surgery, part I. Pathophysiological aspects: update and proposed recommendations. Ann Chir Plast Esthet. 2015;60(1):e3-13.

15. Kuri M, Nakagawa M, Tanaka H, Hasuo S, Kishi Y. Determination of the duration of preoperative smoking cessation to improve wound healing after head and neck surgery. Anesthesiology. 2005; 102(5):892-896. 
16. Weber RS, Berkey BA, Forastiere A, et al. Outcome of salvage total laryngectomy following organ preservation therapy: the Radiation Therapy Oncology Group trial 91-11. Arch Otolaryngol Head Neck Surg. 2003;129(1):44-49.

17. Sayles M, Grant DG. Preventing pharyngo-cutaneous fistula in total laryngectomy: a systematic review and meta-analysis. Laryngoscope. 2014;124(5):1150-1163.

18. Paleri V, Drinnan M, van den Brekel MWM, et al. Vascularized tissue to reduce fistula following salvage total laryngectomy: a systematic review. Laryngoscope. 2014;124(8):1848-1853.

19. Haksever M, Akduman D, Aslan S, Solmaz F, Ozmen S. Modified continuous mucosal connell suture for the pharyngeal closure after total laryngectomy: zipper suture. Clin Exp Otorhinolaryngol. 2015;8(3):281-288.
20. Deniz M, Ciftci Z, Gultekin E. Pharyngoesophageal suturing technique may decrease the incidence of pharyngocutaneous fistula following total laryngectomy. Surg Res Pract. 2015;2015: 363640 .

21. Aires FT, Dedivitis RA, Petrarolha SMP, Bernardo WM, Cernea CR, Brandão LG. Early oral feeding after total laryngectomy: a systematic review. Head Neck. 2015;37(10):1532-1535.

22. Krouse JH, Metson R. Barium swallow is a predictor of salivary fistula following laryngectomy. Otolaryngol-Head Neck Surg Off J Am Acad Otolaryngol-Head Neck Surg. 1992;106(3): 254-257.

23. White HN, Golden B, Sweeny L, Carroll WR, Magnuson JS, Rosenthal EL. Assessment and incidence of salivary leak following laryngectomy. Laryngoscope. 2012;122(8):1796-1799. 